\title{
Structure Activity Relationship (SAR) of Some Benzoic Acid Derivatives from Plant Origin that Exhibit Anti-Sickling Properties in vitro - (Review)
}

\section{Luhata Lokadi Pierre*, Namboole Munkombwe Moses ${ }^{2}$ and Cheuka Mubanga Peter ${ }^{3}$}

${ }^{1}$ Laboratoire de Phytochimie et contrôle qualité, ISAV-Kimwenza, 3724, Kinshasa, The Democratic Republic of Congo (DRC)

'Department of Chemistry, University of Zambia, 32379, Lusaka, Zambia

${ }^{3}$ Department of Chemistry, University of Cape Town, Rondebosch, 7701, South Africa

\begin{abstract}
Anemia or sickle cell disease (SCD) affects millions of people worldwide, mainly in Africa. Strategies to treat sickle cell anemia still focus on prophylactic measures to alleviate the painful crises and prevent adverse effects. Medicinal plants are commonly used in Africa and Asia in the management of SCD. These herbs contain some phytochemicals which exhibit anti-sickling properties in vitro. Benzoic acid derivatives (BADs) seem to play a key role in the bioactivity observed. A combination of medicinal plants containing BADs, amino acids, antioxidant compounds and some minerals could be the best option in designing a phytomedicine against SCD. Justimovi, a food made using the same rationale, is a promising and potent phytomedicine for people suffering from anemia.
\end{abstract}

Keywords: Sickle cell disease; BADs; Aminoacids; Anti-oxidants; Justimovi; Phytomedicine

\section{Introduction}

Sickle cell disease (SCD) is a hereditary blood disorder arising from the replacement of a polar amino acid residue (glutamic acid) by a nonpolar one (valine) at the sixth position of the $\beta$-chain of haemoglobin. At low oxygen tension, the sickle haemoglobin polymerises inside the red blood cell into a gel or further into fibers leading to a drastic increase in the red cell deformability [1,2]. As a result, micro-vascular occlusion arises which can often be fatal [3]. SCD is associated with a number of acute and chronic health problems, such as severe infections, attacks of severe pain ("sickle-cell crisis"), and stroke, with an increased risk of death.

About 300,000 children are born with a form of SCD every year. In 2013, more deaths, 176,000, were recorded compared to 113,000 deaths reported in 1990 [4]. According to reports, Africa is an endemic region of SCD and those afflicated with the disease are estimated at 200,000 per year [5]. The carrier frequency ranges between 10 and $40 \%$ across equatorial Africa, decreasing to $1-2 \%$ on the North African coast and $<1 \%$ in South Africa [6].

Due to the high cost of managing SCD, research has been on-going on the exploration of medicinal plants to address the multiple health challenges presented by the disease [7]. To prevent polymerization of haemoglobin and vascular occlusions, extracts of medicinal plants have been used in folk medicine in the management of SCD. The observed therapeutic effect of these herbs may be as a result of combined antisickling, anti-polymerization, anti-dehydration, anti-inflammatory and antioxidant effects from the components of the plants, which is typical of most herbal remedies.

\section{Benzoic Acid Derivatives (BADS) and Anti-Sickling Properties}

In 1971, Sofowora and his colleagues worked on the root extract of Fagara xanthoxyloides and discovered that the benzoic acid derivatives (BADs) exhibit anti-sickling properties in vitro (Figures 1 and 2). 3,5-Dimethoxy-4-hydroxybenzoic acid or Protocatechuic acid, p-hydroxy- benzoic acid, vanillic acid, syringic acid and ferulic acid were tested in vitro and their anti-sickling properties were confirmed $[8,9]$. $P$-Hydroxy-benzoic acid has also been reported to have antibacterial (against Gram positive and negative bacteria), antifungal, anti-algal, antimutagenic and estrogenic activity [10]. Vanillin is known to inhibit

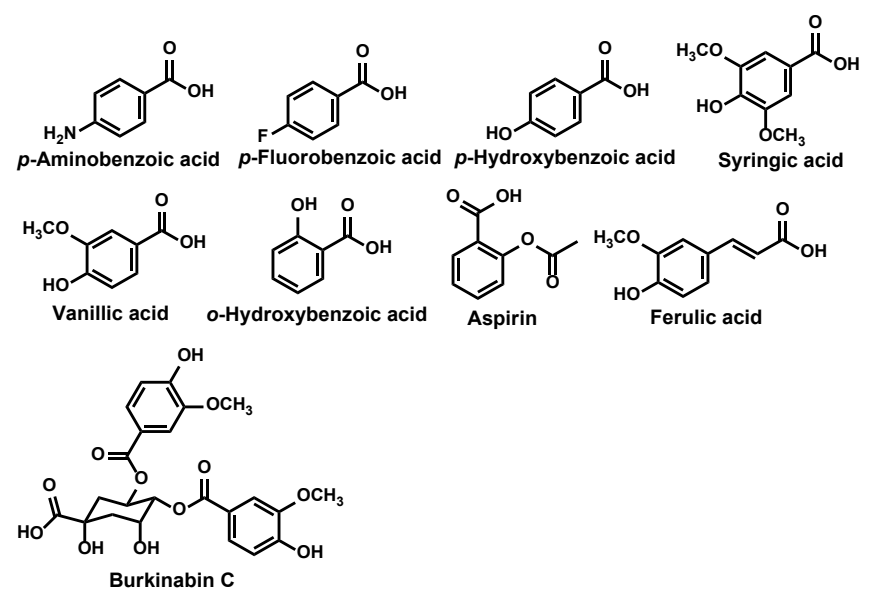

Figure 1: Some BADs from plant origin.

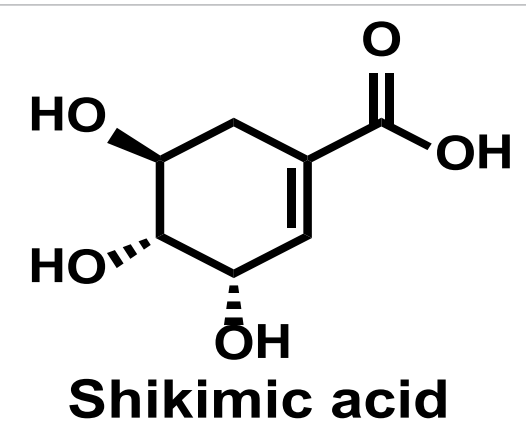

Figure 2: Chemical structure of SKA.

*Corresponding author: Luhata Lokadi Pierre, Directeur du Laboratoire de Phytochimie/Institut Supérieur Agrovétérinaire/ Saint Pierre Canisius- Kimwenza, Kinshasa, The Democratic Republic of Congo (DRC), Tel: +243972056914; E-mail: luhatagot@yahoo.fr

Received May 05, 2015; Accepted May 05, 2015; Published May 13, 2015

Citation: Pierre LL, Moses NM, Peter CM (2015) Structure Activity Relationship (SAR) of Some Benzoic Acid Derivatives from Plant Origin that ExhibitAnti-Sickling Properties in vitro - (Review). Nat Prod Chem Res 3: 176. doi:10.4172/2329-6836.1000176

Copyright: $\odot 2015$ Pierre LL, et al. This is an open-access article distributed under the terms of the Creative Commons Attribution License, which permits unrestricted use, distribution, and reproduction in any medium, provided the original author and source are credited. 
gelation of haemoglobin and markedly increases oxygen affinity of both normal (HbA) and abnormal (HbS) haemoglobin $[11,12])$. The anti-sickling properties of $p$-fluorobenzoic acid have been reported by Elekwa and his colleagues [13]. Burkinabin C, a divanilloylquinic acid found in the root bark of Fagara zanthoxyloides, exhibited anti-sickling properties in vitro (Badioré $\mathrm{O}$, et al.). Ferulic acid is a hydroxycinnamic acid, a type of organic compound. Aromatic aldehydes form Schiff bases with haemoglobin and were designed as potential anti-sickling agents as they reduce the ability of $\mathrm{HbS}$ to polymerise on deoxygenation $[11,12]$. Ferulic acid, like many natural phenols, is an antioxidant in vitro in the sense that it is reactive toward free radicals such as reactive oxygen species (ROS). Its anti-sickling properties were established by [14]

\section{Biosynthesis of BADs}

Many aromatic compounds, particularly BADs and the aromatic amino acids L-phenylalanine, L-tyrosine and L-tryptophan are synthesized through the shikimate pathway. A central intermediate in the pathway is shikimic acid (SKA), a compound which had been isolated from plants of Illicium species 'Japanese'shikimi'.

Diverse biochemical reactions take place during the biosynthesis of SKA namely: aldol-type condensation, hydrolysis, eliminations, phosphorylations, oxidations and reductions reactions using Nicotinamide Adenine Dinucleotide (NAD+), Nicotinamide adenine dinucleotide phosphate (NADH), Adenosine Triphosphate (ATP) and enzymes. Among the aromatic compounds synthesized via shikimate pathway are 4-hydroxybenzoic acid, salicylic acid, $p$-amino benzoic acid (PABA) which forms part of the structure of folic acid (vitamin B9) a molecule used in the management of SCD. Folic acid (Figure 3) is found in yeast, liver, and green vegetables. It is a thermodegradable compound. Though cooking may destroy up to $90 \%$ of the vitamin.

Salicin (Salix species; Salicaceae) is responsible for the analgesic and antipyretic effects of willow barks, widely used for centuries, and the template for synthesis of acetylsalicylic acid (aspirin) as a more effective analogue. Chemically, Aspirin has a similar core structure as Salicin or salicylic acid which is synthesized in microorganisms from isochorismic acid and in plants by two other mechanisms: hydroxylation of benzoic acid (Figure 4) or by side-chain cleavage of 2-coumaric acid, which itself is formed by an ortho-hydroxylation of cinnamic acid.

\section{Mode of Action of Aspirin and NSAIDs}

According to Goodman and Gilman, all non-steroidal antiinflammatory drugs (NSAIDs), including the traditional nonselective

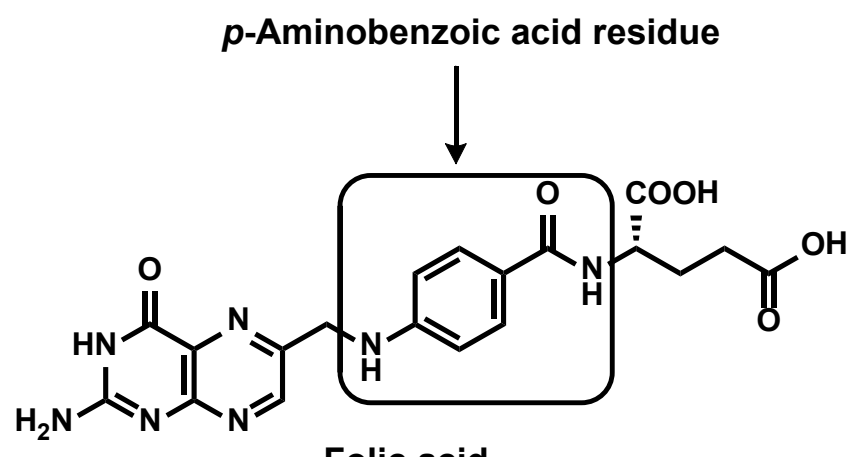

Folic acid

Figure 3: Similarities between PABA and folic acid, a molecule used in the management of SCD. Folic acid is a derivative of PABA. Modifications are observed at the amino and the carboxylic acid groups.
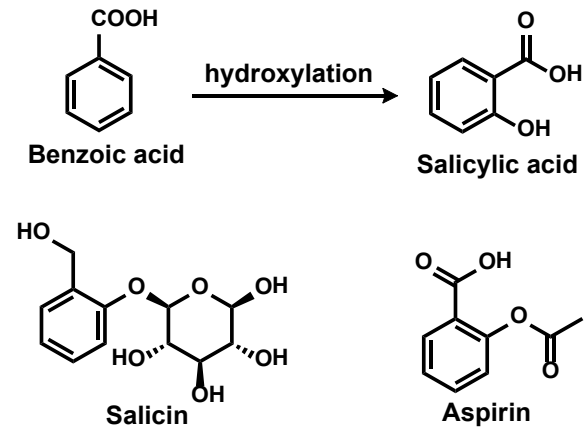

(Acetylsalicylic acid)

Figure 4: Structure similarities between salicin, salicylic acid, and aspirin. These molecules exhibit the same biological activity in vivo.

drugs and the subclass of selective cyclooxygenase-2 (COX-2) inhibitors, are anti-inflammatory, analgesic, and anti-pyretic. NSAIDs are a chemically heterogeneous group of organic acids that share certain therapeutic actions and adverse effects.

The similarities observed in structure can explain why these compounds share the same bioactive properties. The acetyl-3,5dibromosalicylic acid (dibromo aspirin), a derivative of aspirin, has been reported to exhibit the erythrocyte sickling [15]. Acetylation of hemoglobin by aspirin and other acetylating agents has been used to generate haemoglobin analogs with altered structural and functional properties, and may prove useful in the treatment of sickle cell disease [16].

Aspirin inhibits the COX enzymes but in a manner molecularly distinct from the competitive, reversible, active site inhibitors and is often distinguished from the NSAIDs. In fact, Aspirin and tNSAIDs inhibit the biosynthesis of Prostaglandins in all cell types whenever cells are damaged.

\section{Structure Activity Relationship of BADs}

Understanding of the structural features that are crucial to antisickling activity of anti-sickling agents is critically important in the design of new chemical entities to treat and/or cure SCD. In this regard, a number of structure activity relationship studies employing both in silico and experimental techniques have been reported. In this review, we focus on SAR studies around antisickling agents possessing a benzoic acid core scaffold and other related derivatives.

Mathematical modeling techniques have been employed in predicting the antisickling activities of benzoic acid derivatives. Employing such mathematical modeling approaches, Fasanmade et al. [17] were able to derive a quantitative structure activity relationship from a series of synthetic benzoic acid derivatives. Derivatives predicted to be active by the mathematical model were tested experimentally and these included $p$-toluic acid, $p$-dimethylaminobenzoic acid, $p$-fluorobenzoic acid, $p$-chlorobenzoic acid, $m$-chlorobenzoic acid, $p$-bromobenzoic acid, $p$-nitrobenzoic acid, and $p$-iodobenzoic acid (Figures 5-7).

The anti-sickling activities (the ability to induce normal morphology to deoxygenated and sickle-shaped red blood cells) of these benzoic acid derivatives were predicted by the Hansch lipophilicity pi $(\pi)$ and the Hammett electronic sigma $(\sigma)$ constants. After analyzing a series of equations correlating biological activities with the structures of the tested derivatives, Fasanmade et al. [17] concluded: strong electron donating groups attached on the benzene ring with average lipophilicity 


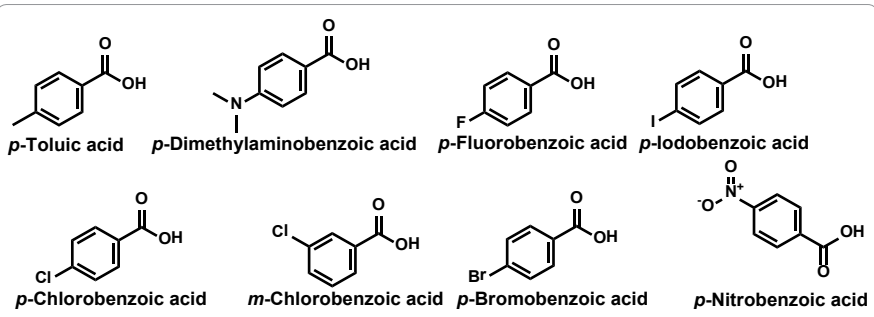

Figure 5: Benzoic acid derivatives with anti-sickling activity predicted by a mathematical model.
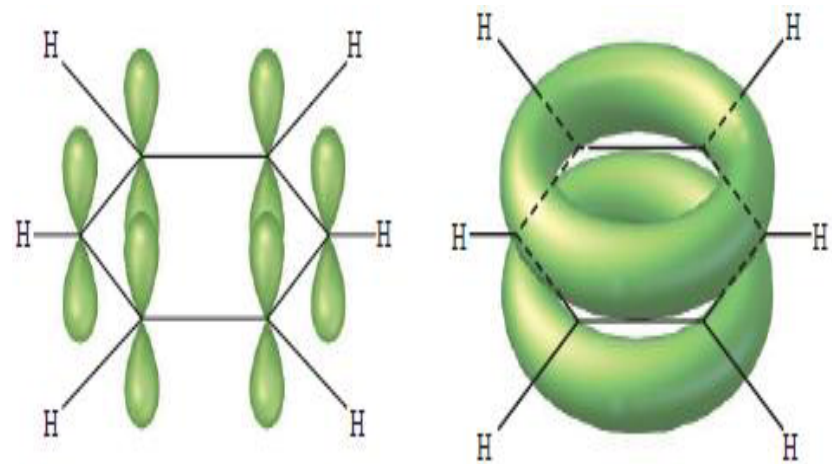

Figure 6: The planar structure of Benzene.

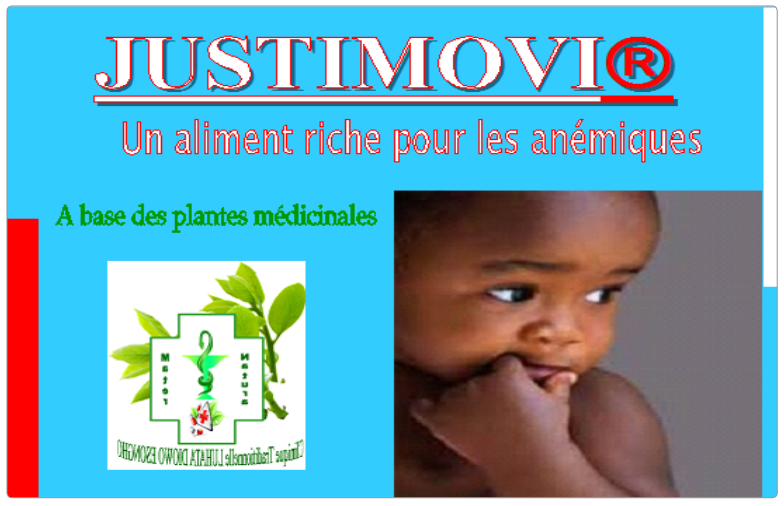

Figure 7: Justimovi, a food for people suffering from SCD.

are an important feature for such benzoic acid derivatives to possess potent antisickling activity.

Other studies have also revealed promising antisickling activity of benzoic acid derivatives. In 1984, Abraham et al. reported the design, synthesis, and anti-sickling evaluation of disubstituted benzoic acids [18]. The designing of the disubstituted benzoic acid derivatives involved the use of molecular modeling techniques. Such a design ensured the strategic positioning of functional groups to facilitate their interaction with several polar amino acid residues near the Valine-6 beta mutation site in sickled haemoglobin (HbS). A hydrophobic group (the phenyl core) was also rationally incorporated to occupy a nonpolar area on the surface of the protein created by several hydrophobic amino acids. Synthesis and antigelling evaluation of these rationally designed target compounds gave rise to derivatives with promising antisickling activities. For structural details of such compounds, the reader is referred to the original research article [18].

From such studies, therefore, it appears two structural features are crucial to potent activity of anti-sickling chemotherapeutic agents.
Firstly, hydrophilic substituents on the phenyl ring are necessary to facilitate interaction and binding to polar amino acid residues near the mutation site. Secondly, a phenyl core is critically important to enhance hydrophobic interactions with several hydrophobic amino acids. The aromatic moiety seems to play an important role in the bioactivity of BADs. The $\mathrm{sp}^{2}$ hybridized carbons make these molecules planar, a characteristic that facilitates binding to drug target binding pockets. This results in anti-inflammatory, analgesic, and antipyretic activity. It has been proposed that the pi $(\pi)$ electronic system present in alkynes and aromatic rings are regions of high electron density and can act as hydrogen bond acceptors. [19].

The carboxylic groups attached to the phenyl ring are moderate hydrogen bond acceptors/donors. Furthermore, ethers, alcohols, phenols, amides, amines and ketones act as hydrogen bond acceptors and/or donors. These groups can in vivo form moderately strong hydrogen bonds, therefore, conferring potent bioactivity.

\section{Management of Sickle Cell Disease Using Medicinal Plants}

Plants produce a large number of molecules which can be used in the management of SCD. In most parts of developing countries, medicinal plants have been used in the treatment of painful crises associated with SCD, especially among the lower socio-economic class who cannot afford the high cost of western medicine [20].

A number of plants used in traditional medicine have been investigated. Some of them exhibited anti-sickling properties in vitro. These include Piper guineensis, Pterocarpa osun, Eugenia caryophyllala and Sorghum bicolor [21]; Fagara zanthoxyloides [22]; Cajanus cajan [23]; Vigna unguiculata [24]; Carica papaya [25,26]; and Justicia secunda $([27,28]$.

The phytochemistry of these plants reveals the presence of BADs, amino acids, anti-oxidants, alkaloids, minerals etc. Phenolic and polyphenolics are known to possess excellent anti-oxidant activities, and may play a significant role in SCD management. Phenylalanine particularly has been found to be a potent inhibitor of HbS gelation and acts by competing for the protein-protein contact sites within the $\mathrm{HbS}$ polymer, which may also be the mechanism of action of other antisickling amino acids and peptides [29].

A combination of vegetables and foods which are rich in BADs, amino acids, and anti-oxidants can be prescribed as phytomedicines to people suffering from SCD. Using the same rationale, the Laboratoire de phytochimie/Isav-kimwenza has made a food (JUSTIMOVI) which possesses the properties of reducing vasocclusive crises and attacks of severe pain.

\section{Conclusion}

SCD remains a big challenge for researchers. New research efforts and approaches in the management of this blood disorder are ongoing. Some of these treatment options are very expensive and beyond the reach of many. To overcome this problem, scientific investigations have proved the necessity of incorporating medicinal plants in the management of SCD. The analgesic, antipyretic, and anti-sickling properties of BADs seem to be important in designing a potent phytomedicine. BADs, amino-acids, anti-oxidants, and some minerals $(\mathrm{K}, \mathrm{Mg}, \mathrm{Ca}, \mathrm{Fe})$ together can improve the quality of health for people suffering from SCD. On the basis of phytochemistry and pharmacology studies, Justimovi is an example of phytomedicine against anemia. 
Citation: Pierre LL, Moses NM, Peter CM (2015) Structure Activity Relationship (SAR) of Some Benzoic Acid Derivatives from Plant Origin that Exhibit AntiSickling Properties in vitro - (Review). Nat Prod Chem Res 3: 176. doi:10.4172/2329-6836.1000176

\section{Acknowledgments}

We are very grateful to De la Kethulle Henri, Sj, Michel N'tangu, Sj and the Croisade Nationale Drépanocytose (CND) for the financial support.

\section{References}

1. Afolabi IS, Osikoya IO, Fajimi OD, Usoro PI, Ogunleye DO, et al. (2012) Solenostemon monostachyus, Ipomoea involucrata and Carica papaya seed oil versus Glutathione, or Vernonia amygdalina: methanolic extracts of nove plants for the management of sickle cell anemia disease. BMC Complement Altern Med 12: 262.

2. Chikezie PC, Chikezie CM, Amaragbulem PI (2011) Polymerization of human sickle cell haemoglobin $(\mathrm{HbS})$ in the presence of three antimalarial drugs. African Journal of Biochemistry Research 5: 39-42.

3. Olufunmilayo EA, Adelodun LK, Oladimeji PR, Lateef SK (2010) In vitro antisickling activities and phytochemical evaluation of Plumbago zeylanica and Uvaria chamae. African Journal of Biotechnology 9: 9032-9036.

4. GBD 2013 Mortality and Causes of Death, Collaborators (2015) Global, regional and national age-sex specific all-cause and cause-specific mortality for 240 causes of death, 1990-2013: a systematic analysis for the Global Burden of Disease Study 2013. The Lancet 385: 117-171.

5. Diallo D, Tchernia G (2002) Sickle cell disease in Africa. Curr Opin Hematol 9 111-116.

6. WHO (2006) Sickle-cell anaemia - Report by the Secretariat.

7. Kunle OF, Egharevba $\mathrm{HO}$ (2013) Chemical constituents and biological activity of medicinal plants used for the management of sickle cell disease - A review. Journal of Medicinal Plants Research 7: 3452-3476.

8. Sofowora EA, Isaac-Sodeye WA, Ogunkoya LO (1975) Isolation and characterisation of an antisickling agent from Fagara zanthoxyloides root. Lloydia 38: 169-171.

9. Moody JO, Ojo OO, Omotade OO, Adeyemo AA, Olumese PE, et al. (2003) Anti-sickling potential of a Nigerian herbal formula (ajawaron $\mathrm{HF}$ ) and the majo plant component (Cissus populnea L. CPK). Phytother Res 17: 1173-1176.

10. Rohini Manuja, Shikha Sachdeva, Akash Jain, Jasmine Chaudhary (2013) A Comprehensive Review on Biological Activities of P-Hydroxy Benzoic Acid and Its Derivatives. Int J Pharm Sci Rev Res 22: 109-115.

11. Zaugg RH, Walder JA, Klotz IM (1977) Schiff base adducts of hemoglobin Modifications that inhibit erythrocyte sickling. J Biol Chem 252: 8542-8548.

12. Abraham DJ, Mehanna AS, Wireko FC, Whitney J, Thomas RP, et al. (1991) Vanillin, a potential agent for the treatment of sickle cell anemia. Blood 77 1334-1341.

13. Elekwa I, Monanu MO, Anosike EO (2005) In vitro effects of aqueous extracts of Zanthxylum macrophyla roots on adenosine triphosphatases from human erythrocytes of different genotypes. Biokemistri 17: 19-25.
14. Elujoba AA, Nagels L, Sofowora A, VanDongen W (1989) Chromatographic analysis of antisickling compounds in Zanthoxylum species. International Journal of Pharmaceutics 53: R1-R3.

15. Walder JA, Zaugg RH, Iwaoka RS, Watkin WG, Klotz IM (1977) Alternative aspirins as antisickling agents: acetyl-3,5-dibromosalicylic acid. Proc Natl Acad Sci U S A 74: 5499-5503.

16. Xu AS, Macdonald JM, Labotka RJ, London RE (1999) NMR study of the sites of human hemoglobin acetylated by aspirin. Biochim Biophys Acta 1432: 333349.

17. Fasanmade AA Olaniyi AA Ab-Yisak W (1994) Mathematical models of antisickling activities of benzoic acid derivatives on red blood cells of sicklers. Afr J Med Med Sci 23: 369-377.

18. Abraham DJ, Gazze DM, Kennedy PE, Mokotoff M (1984) Design, synthesis, and testing of potential antisickling agents. 5. Disubstituted benzoic acids designed for the donor site and proline salicylates designed for the acceptor site. J Med Chem 27:1549-1559.

19. Ouattara B, Jansen O, Angenot L, Guissou IP, Frédérich M, et al. (2009) Antisickling properties of divanilloylquinic acids isolated from Fagara zanthoxyloides Lam. (Rutaceae). Phytomedicine 16: 125-129.

20. Joy Okpuzor, Olumide Adebesin, Henriatta Ogbunugafor, Ifeanyi Amad (2008) The potential of medicinal plants in sickle cell disease control: A review. International Journal of Biomedical and Health Sciences 4: 1-9.

21. Wambebe C, Khamofu H, Momoh JA, Ekpeyong M, Audu BS, et al. (2001) Double-blind, placebo-controlled, randomised cross-over clinical trial of NIPRISAN in patients with Sickle Cell Disorder. Phytomedicine 8: 252-261.

22. Sofowora EA, Isaacs WA (1971) Reversal of sickling and crenation in erythrocytes by the root extract of Fagara zanthoxyloides. Lloydia 34: 383-385.

23. Ogoda Onah J, Akubue PI, Okide GB (2002) The kinetics of reversal of presickled erythrocytes by the aqueous extract of Cajanus cajan seeds. Phytother Res 16: 748-750.

24. Mpiana PT, Tshibangu DS, Shetonde OM, Ngbolua KN (2007) In vitro antidrepanocytary actvity (anti-sickle cell anemia) of some congolese plants. Phytomedicine 14: 192-195.

25. Oduola T, Adeniyi FAA, Ogunyemi EO, Bello IS, Idowu TO (2006) Antisickling agent in an extract of unripe pawpaw (Carica papaya): Is it real?. African Journal of Biotechnology 5: 1947-1949.

26. Thomas KD, Ajani B (1987) Antisickling agent in an extract of unripe pawpaw fruit (Carica papaya). Trans R Soc Trop Med Hyg 81: 510-511.

27. N'Guessan K, Kouassi KH, Ouattara D (2010) Plants used to treat anaemia, in traditional medicine, by Abbey and Krobou populations, in the South of Côted'Ivoire. Journal of Applied Sciences Research 6: 1291-2197.

28. Correa GM, Alcântara AFC (2012) Chemical constituents and biologica activities of species of Justicia - a review. Braz J Pharmacogn 22: 220-238.

29. Dean J, Schechter AN (1978) Sickle cell anaemia: molecular and cellular basis of therapeutic approaches (first of three parts). N Engl J Med 299: 863-870. 